\title{
Commentary: Multiscale Analysis of Independent Alzheimer's Cohorts Finds Disruption of Molecular, Genetic, and Clinical Networks by Human Herpesvirus
}

\author{
Xiao-Wen Sun 1,2, Chang-Mei Liu ${ }^{1,2,3}$ and Zhao-Qian Teng ${ }^{1,2,3 *}$ \\ ${ }^{1}$ State Key Laboratory of Stem Cell and Reproductive Biology, Institute of Zoology, Chinese Academy of Sciences, Beijing, \\ China, ${ }^{2}$ University of Chinese Academy of Sciences, Beijing, China, ${ }^{3}$ Institute of Stem Cell and Regeneration, Chinese \\ Academy of Sciences, Beijing, China
}

Keywords: alzheier disease, herpes virus, miR-155 inhibition, HHV 6, HHV 7

\section{A Commentary on}

Multiscale Analysis of Independent Alzheimer's Cohorts Finds Disruption of Molecular, Genetic, and Clinical Networks by Human Herpesvirus

by Readhead, B., Haure-Mirande, J. V., Funk, C. C., Richards, M. A., Shannon, P., Haroutunian, V., et al. (2018). Neuron 99, 64.e7-82.e7. doi: 10.1016/j.neuron.2018.05.023

OPEN ACCESS

Edited by:

Nikhat Ahmed,

Barrett Hodgson University, Pakistan

Reviewed by:

Robert David Moir

Massachusetts General Hospital,

Harvard Medical School,

United States

*Correspondence:

Zhao-Qian Teng

tengzq@ioz.ac.cn

Received: 12 July 2018

Accepted: 29 August 2018

Published: 20 September 2018

Citation:

Sun X-W, Liu C-M and Teng Z-Q

(2018) Commentary: Multiscale Analysis of Independent Alzheimer's

Cohorts Finds Disruption of Molecular,

Genetic, and Clinical Networks by

Human Herpesvirus.

Front. Mol. Neurosci. 11:340.

doi: 10.3389/fnmol.2018.00340
Alzheimer's disease (AD), the most common type of dementia among the elderly, is caused by progressive neural death that results in impaired memory, thinking skills and, eventually, the ability to carry out simple tasks. Unfortunately, approximately $5 \%$ of people over the age of 65 suffer from $\mathrm{AD}$, and the prevalence of $\mathrm{AD}$ increases with aging (Udeochu et al., 2018). Pathological deposition and accumulation of $\beta$-amyloid $(A \beta)$ into senile plaques and hyperphosphorylated Tau into neurofibrillary tangles are widely acknowledged hallmarks of AD (Frere and Slutsky, 2018). The amyloid cascade hypothesis posits that $\mathrm{A} \beta$ is the key trigger of $\mathrm{AD}$ pathology (Hardy and Selkoe, 2002; Musiek and Holtzman, 2015; Selkoe and Hardy, 2016). However, following repeated failures of $A \beta$-targeted medicine therapeutics, it has been argued that $A \beta$ may does not play a prominent role in the symptomatic stages of this disease, or the progression of $\mathrm{AD}$ cannot been rescued after the emergence of symptom. Understanding the earliest causal elements of AD is difficult for its borderless and protracted preclinical process, and lack of available staged brain tissue samples (Zhang et al., 2013). Therefore the initiating events and earliest drivers that eventually lead to clinical AD symptoms still remain controversial (Poo et al., 2016).

Investigators have proposed that the onset and progression of $\mathrm{AD}$ is contributed by pathogenic microbes although definitive evidence has not been presented (Sjogren et al., 1952; Middleton et al., 1980; Itzhaki, 2014). A recent report published in the June 21 issue of the journal Neuron by Dr. Ben Readhead and colleagues at Icahn School of Medicine at Mount Sinai provides novel evidence that viral species, particularly, particularly human herpesviruses HHV-6A and HHV-7, may have been potential earliest drivers which regulate molecular, clinical, and neuropathological networks of $\mathrm{AD}$. To examine whether viral activity constitutes a general feature of $\mathrm{AD}$, they started to map and compare biological networks underlying the preclinical $\mathrm{AD}$ (brains meeting neuropathological criteria for $\mathrm{AD}$ from individuals who were cognitively intact at the time of death) using multiple independent datasets collected from human subjects. They found that $\mathrm{C} 2 \mathrm{H} 2$ zinc finger transcription factor $(\mathrm{C} 2 \mathrm{H} 2-\mathrm{TF})$ binding motifs and G-quadruplex (G4) sequences are strongly enriched among the promoters of genes that present 
only in the preclinical AD network ("Gained in preclinical AD") and those present only in the network ("Lost in preclinical AD"), suggesting a potential role for virus-mediated network activities in $\mathrm{AD}$. To directly examine viral sequences, they examined four, large multi-omic datasets and observed the presence of many viral species in the aging brain and linked multiple viral species with regulation of $\mathrm{AD}$ genetic risk networks, $\mathrm{AD}$ gene expression changes, and association with clinical dementia rating and neuropathology burden. By comparing datasets among different independent cohorts or between $\mathrm{AD}$ and other neuropathological controls, they found that viral genes in HHV-6A and HHV-7 appear at least partly specific to $\mathrm{AD}$, although $\mathrm{HHV}-6 \mathrm{~A}$ may also be relevant to other diseases such as progressive supranuclear palsy (PSP). They then extended their analysis of the association between viral gene RNA abundance and AD-relevant clinical and neuropathological traits, and found miR-155 inhibition by HHV-6A, as described in HHV-6A infected T cells (Caselli et al., 2017). Molecular and functional enrichments of the miR-155-KO differentially expressed genes suggested that miR-155 might play a key role in host response to AD-relevant viral perturbation, and act as a potential mediator of neuronal loss.

Based on unbiased approaches and large-scale data sets from several brain banks and cohort studies, this is the first study to provide strong evidence supporting the controversial hypothesis that viruses play an essential role in regulatory genetic networks that are believed to lead to AD. Identifying links to viruses may help scientists interested in developing potential new treatment strategies.

Several important questions are raised from this phenomenal study. First, does herpes virus cause the onset or progression of $\mathrm{AD}$ ? Eimer and colleagues recently reported that $\mathrm{A} \beta$ traps herpes viruses in insoluble amyloid, and active herpes infections in brain accelerate amyloid deposition, indicating that herpes infection may promote $\mathrm{AD}$ pathology directly via amyloid-mediated pathological pathways (Eimer et al., 2018). HHV-6 and -7 are no longer considered benign but are now recognized as significant causes of viral encephalitis, particularly in immunocompromised individuals, and have also been shown to be associated with demyelinating brain diseases and epilepsy (Sellner and Trinka, 2012; Campbell et al., 2017). As this study has identified a clear link between herpes viral DNA sequences and activation of molecular, genetic and clinical aspects of $\mathrm{AD}$, future studies are necessary to explore the nature of this link.

Second, whether herpesviruses regulate, or are regulated by $\mathrm{AD}$-associated genes? Will anti-herpes drugs be effective against

\section{REFERENCES}

Berneman, Z. N., Ablashi, D. V., Li, G., Eger-Fletcher, M., Reitz, M. S. Jr., Hung, C. L., et al. (1992). Human herpesvirus 7 is a T-lymphotropic virus and is related to, but significantly different from, human herpesvirus 6 and human cytomegalovirus. Proc. Natl. Acad. Sci. U.S.A. 89, 10552-10556. doi: 10.1073/pnas.89.21.10552

Campbell, A., Hogestyn, J. M., Folts, C. J., Lopez, B., Pröschel, C., Mock, D., et al. (2017). Expression of the human herpesvirus 6A latency-associated transcript U94A disrupts human oligodendrocyte progenitor migration. Sci. Rep. 7:3978. doi: 10.1038/s41598-017-04432-y early onset of $\mathrm{AD}$ ? This study established a strong connection between multiple viruses, especially HHV-6A, and AD risk genes, including PSEN1, BACE1, and APBB2 which are implicated in regulation of $A \beta$ production. Besides, several recent studies show that $A \beta$ is an antimicrobial protein of the body's innate immune system, capable of providing immediate, effective protection from infection with pathogens like herpes viruses in both cultured human brain cells and animal models of AD (Kumar et al., 2016; Eimer et al., 2018). Virus-host protein and RNA networks revealed by this study suggest many potentially fruitful avenues for future investigations of mechanism and treatment for AD.

Third, is miR-155 a regulator of anti- or pro-viral activity in early $\mathrm{AD}$ ? Could miR-155 gain-of-function help with $\mathrm{A} \beta$ clearance and neuroprotection in $\mathrm{AD}$ ? MiR-155 has been reported as an important regulator of $\mathrm{T}$ cell and microglia in response to neurodegeneration (Song and Lee, 2015; Krasemann et al., 2017). The miR-155 immune network offers a targeted area for developing effective drugs for treating AD.

Lastly, there remain some open issues that future studies will need to address about the Readhead et al. findings. For example, HHV-6A/B and HHV-7 are considered lymphotropic rather than neurotrophic (Berneman et al., 1992; Mori, 2009). Although neither terms are entirely accurate, this characterization does serve to illustrate these viruses principally target $T$ cells and macrophage. In $\mathrm{AD}$ there is significant infiltration into brain by macrophages and $\mathrm{T}$ and B cells (Lindsay and Christian, 2015). Thus, it is possible that the viral signal seen by Readhead et al originated in the periphery. This will need to be addressed in future studies.

\section{AUTHOR CONTRIBUTIONS}

X-WS drafted an initial version of this commentary. C-ML and Z-QT revised and finalized the text. All authors approved it for publication.

\section{ACKNOWLEDGMENTS}

This work was supported by grants from the National Key Research and Development Program of China Project (2018YFA0108001, 2016YFA0101402), the Strategic Priority Research Program of the Chinese Academy of Sciences (XDA16010300), and the National Science Foundation of China (No. 81571212, 81771224). doi: $10.1186 /$ s12985-016-0672-6

Eimer, W. A., Vijaya Kumar, D. K., Navalpur Shanmugam, N. K., Rodriguez, A. S., Mitchell, T., Washicosky, K. J., et al. (2018). Alzheimer's disease-associated $\beta$-amyloid is rapidly seeded by herpesviridae to protect against brain infection. Neuron 99, 56.e3-63.e3. doi: 10.1016/j.neuron.2018.06.030

Frere, S., and Slutsky, I. (2018). Alzheimer's disease: from firing instability to homeostasis network collapse. Neuron 97, 32-58. doi: 10.1016/j.neuron.2017.11.028 
Hardy, J., and Selkoe, D. J. (2002). The amyloid hypothesis of Alzheimer's disease: progress and problems on the road to therapeutics. Science 297, 353-356. doi: $10.1126 /$ science. 1072994

Itzhaki, R. F. (2014). Herpes simplex virus type 1 and Alzheimer's disease: increasing evidence for a major role of the virus. Front. Aging Neurosci. 6:202. doi: 10.3389/fnagi.2014.00202

Krasemann, S., Madore, C., Cialic, R., Baufeld, C., Calcagno, N., El Fatimy, R., et al. (2017). The TREM2-APOE pathway drives the transcriptional phenotype of dysfunctional microglia in neurodegenerative diseases. Immunity 47, 566-581. doi: 10.1016/j.immuni.2017.08.008

Kumar, D. K., Choi, S. H., Washicosky, K. J., Eimer, W. A., Tucker, S., Ghofrani, J., et al. (2016). Amyloid- $\beta$ peptide protects against microbial infection in mouse and worm models of Alzheimer's disease. Sci. Transl. Med. 8:340ra72. doi: 10.1126/scitranslmed.aaf1059

Lindsay, A. H., and Christian, H. (2015). Migration of blood cells to $\beta$-amyloid plaques in Alzheimer's disease. Exp. Gerontol. 65, 8-15. doi: 10.1016/j.exger.2015.03.002

Middleton, P. J., Petric, M., Kozak, M., Rewcastle, N. B., and McLachlan D. R. (1980). Herpes-simplex viral genome and senile and presenile dementias of Alzheimer and pick. Lancet 315:1038. doi: 10.1016/S0140-6736(80)91490-7

Mori, Y. (2009). Recent topics related to human herpesvirus 6 cell tropism. Cell. Microbiol. 11, 1001-1006. doi: 10.1111/j.1462-5822.2009.01312.x

Musiek, E. S., and Holtzman, D. M. (2015). Three dimensions of the amyloid hypothesis: time, space and 'wingmen'. Nat. Neurosci. 18, 800-806. doi: $10.1038 / \mathrm{nn} .4018$

Poo, M. M., Pignatelli, M., Ryan, T. J., Tonegawa, S., Bonhoeffer, T., Martin, K. C., et al. (2016). What is memory? The present state of the engram. BMC Biol. 14:40. doi: 10.1186/s12915-016-0261-6
Selkoe, D. J., and Hardy, J. (2016). The amyloid hypothesis of Alzheimer's disease at 25 years. EMBO Mol. Med. 8, 595-608. doi: 10.15252/emmm.201606210

Sellner, J., and Trinka, E. (2012). Seizures and epilepsy in herpes simplex virus encephalitis: current concepts and future directions of pathogenesis and management. J Neurol. 259, 2019-2030. doi: 10.1007/s00415-012-6494-6

Sjogren, T., Sjogren, H., and Lindgren, A. G. (1952). Morbus Alzheimer and morbus Pick; a genetic, clinical and patho-anatomical study. Acta Psychiatr. Neurol. Scand. Suppl. 82, 1-152.

Song, J., and Lee, J. E. (2015). miR-155 is involved in Alzheimer's disease by regulating $\mathrm{T}$ lymphocyte function. Front. Aging Neurosci. 7:61. doi: 10.3389/fnagi.2015.00061

Udeochu, J., Sayed, F. A., and Gan, L. (2018). TREM2 and amyloid beta: a love-hate relationship. Neuron 97, 991-993. doi: 10.1016/j.neuron.2018.02.018

Zhang, B., Gaiteri, C., Bodea, L. G., Wang, Z., McElwee, J., Podtelezhnikov, A. A., et al. (2013). Integrated systems approach identifies genetic nodes and networks in lateonset Alzheimer's disease. Cell 153, 707-720. doi: $10.1016 /$ j.cell.2013.03.030

Conflict of Interest Statement: The authors declare that the research was conducted in the absence of any commercial or financial relationships that could be construed as a potential conflict of interest.

Copyright (c) 2018 Sun, Liu and Teng. This is an open-access article distributed under the terms of the Creative Commons Attribution License (CC BY). The use, distribution or reproduction in other forums is permitted, provided the original author(s) and the copyright owner(s) are credited and that the original publication in this journal is cited, in accordance with accepted academic practice. No use, distribution or reproduction is permitted which does not comply with these terms. 